\title{
A novel gene that is up-regulated during recovery from cold shock in Drosophila melanogaster
}

\author{
Shin G. Goto
}

\begin{tabular}{|c|l|}
\hline Citation & Gene,270(1-2): 259-264 \\
\hline Issue Date & 2001-05-30 \\
\hline \multicolumn{1}{c|}{ Type } & Journal Article \\
\hline Textversion & author \\
\hline & $\begin{array}{l}\text { C 2001Elsevier Science B.V. All rights reserved. This manuscript version is made } \\
\text { available under the CC-BY-NC-ND 4.0 License. } \\
\text { https://creativecommons.org/licenses/by-nc-nd/4.0/. }\end{array}$ \\
Rights & $\begin{array}{l}\text { This is the accept manuscript version. The article has been published in final form at } \\
\text { http://doi.org/10.1016/S0378-1119(01)00465-6. }\end{array}$ \\
& $\begin{array}{l}\text { Please cite only the published version. } \\
\text { 引用の際には出版社版をご確認ご利用ください。 }\end{array}$ \\
\hline DOI & 10.1016/S0378-1119(01)00465-6 \\
\hline
\end{tabular}

\author{
Self-Archiving by Author(s) \\ Placed on: Osaka City University
}




\title{
A novel gene that is up-regulated during recovery from cold shock in Drosophila melanogaster
}

\author{
Shin G. Goto \\ Graduate School of Environmental Earth Science, Hokkaido University, Sapporo, Hokkaido 060-0810, Japan
}

\begin{abstract}
Gene expression during recovery at $25^{\circ} \mathrm{C}$ (rearing temperature) after cold shock $\left(0^{\circ} \mathrm{C}\right)$ was studied in Drosophila melanogaster using a subtraction technique. A novel gene (Frost, abbreviated as Fst) was considerably up-regulated during recovery after cold shock. In addition, a prolongation of cold shock was more effective for induction. In contrast to cold shock, Fst gene did not respond to heat shock. This gene is apparently the same as the unidentified gene, CG9434. Fst has high internal repeats not only in nucleotide but also in amino acid sequences. In addition, FST protein has a proline-rich region. The deduced amino acid sequence revealed a modular structure; i.e., a signal peptide in the N-terminal region followed by a long hydrophilic region. Therefore, this protein is likely to be directed into ER and secreted into extracellular space.
\end{abstract}

\section{Introduction}

Sudden exposure to low temperature causes severe damage to organisms and their tissues, and normally elicits the expression of stress proteins. However, if organisms are first exposed to low but non-freezing temperatures they undergo cold acclimation that increases their tolerance to subsequent low temperature exposure. A variety of biochemical and physiological changes occur during cold acclimation (Thomashow, 1990). In addition, changes in gene expression after cold treatment appear to be related to cold acclimation at least in plants (for example, Goodwin et al., 1996; Knight et al., 1996, 1997; Monroy et al., 1998).

In insects, it has been reported that heat-shock proteins (HSPs) play an important role in the acquisition of cold tolerance. Denlinger et al. (1992) observed in Lymantria dispar that chilled eggs are more tolerant to cold and express stress proteins more abundantly than unchilled ones. In addition, there are observations that cold shock elicits HSP expression and prior exposure to mildly elevated temperatures reduces cold-shock injury in Drosophila and Sarcophaga (reviewed by Denlinger et al., 1991). Moreover, it is well known in many cold-water marine fish and terrestrial arthropods that hemolymph or blood proteins such as anti-freeze proteins (AFPs or thermal hysteresis proteins; THPs) and their activator proteins contribute to cold tolerance (reviewed by Duman et al., 1991). On the other hand, it has been reported in plants that an elevation of cytosolic Ca ${ }^{2+}$ is involved in environmental stresses (for example, Knight et al., 1996, 1997). In addition, Perotti et al. (1990) reported in human cells that cold shock resulted in endonuclease activation and apoptosis: the prolonged elevation of cytosolic free Ca ${ }^{2+}$ induces apoptosis by stimulating $\mathrm{Ca}^{2+} / \mathrm{Mg}^{2+}$-dependent endonucleases and modulating $\mathrm{Ca}^{2+} / \mathrm{Calmodulin}$ dependent enzymatic activities (Knight et al., 1996, 1997). This link among $\mathrm{Ca}^{2+}$, cold stress and the expression of stress-inducible Ca ${ }^{2+}$-binding protein (DCA) was reported in Drosophila melanogaster (Goto, 2000).

However, there have been few reports of genes other than AFP, HSP and DCA in cold tolerance or acclimation in insects. Here I report the discovery of a gene that responds to cold shock in $D$. melanogaster.

\section{Materials and methods}

\subsection{Flies}

D. melanogaster Meigen (Canton S strain) was maintained under laboratory conditions (continuous light at $25^{\circ} \mathrm{C}$ ) on cornmeal-malt medium, and used for experiments 7 days after eclosion.

\subsection{Cold and heat shock}

Prior to experiments, vials that contained food medium were cooled $\left(0^{\circ} \mathrm{C}\right)$ or warmed $\left(37^{\circ} \mathrm{C}\right)$. Flies maintained at $25^{\circ} \mathrm{C}$ were transferred to cooled or warmed vials and exposed to cold $\left(0^{\circ} \mathrm{C}\right)$ for 2 or $8 \mathrm{~h}$ or heat $\left(37^{\circ} \mathrm{C}\right)$ for 30 min. After cold shock, flies were allowed to recover at $25^{\circ} \mathrm{C}$ for $2 \mathrm{~h}$. On the other hand, heat-shocked flies were used for experiments just after the exposure. 
All flies entered a coma within $1 \mathrm{~min}$ after the onset of the heat or cold exposure, but they recovered from the coma within 10 min when they were returned to $25^{\circ} \mathrm{C}$.

\subsection{RNA extraction and mRNA purification}

RNA extraction and poly(A)+ RNA purification were performed using RNAzol B (TEL-TEST) and Dynabeads mRNA purification kit (DYNAL) according to the suppliers' instructions.

\subsection{Subtraction, differential screening and RACE}

These techniques were performed using Clontech PCR-Select cDNA Subtraction kit, PCR-Select Differential Screening kit and Marathon cDNA Amplification kit (Clontech).

In this experiment, the cDNAs synthesized from flies reared at $25^{\circ} \mathrm{C}$ as adults for 7 days and from 7 days old flies that were cold shocked at $0^{\circ} \mathrm{C}$ for $8 \mathrm{~h}$ and then returned to $25^{\circ} \mathrm{C}$ for $2 \mathrm{~h}$ were used for the subtraction. In addition, cDNA derived from the forward subtraction (non-shocked subtracted from cold shocked) and cDNA derived from the reverse subtraction (cold shocked subtracted from nonshocked) were referred to as cold-shock-enriched and control-enriched cDNAs, respectively.

\subsection{Northern hybridization}

Poly(A)+ RNAs were electrophoresed on denaturing gels and transferred to nylon membranes according to Sambrook et al. (1989). The probe was labeled using a DIG DNA Labeling kit (Boehringer Mannheim) according to the supplier's instruction. Hybridization and detection were performed using a DIG DNA Luminescent Detection kit (Boehringer Mannheim). $D$. melanogaster $r p 49$ gene probe was used as a control. All experiments were conducted in triplicate and representative blots are shown.

\subsection{Sequencing}

Plasmids were purified using QIAprep Spin Miniprep kit (QIAGEN). The sequence was obtained from a 373A DNA sequencer (PE Applied Biosystems) using Dye Primer and Dye Terminator Cycle Sequencing FS Ready Reaction kits (PE Applied Biosystems).

\section{Results and discussion}

\subsection{Selective PCR amplification and differential screening}

After the selective PCR amplification, cold-shock-enriched cDNAs were subcloned into pGEM-T vector (Promega). For differential screening, 94 fragments were amplified with PCR and blotted onto two membranes. Among them, five clones showed stronger signals when detected using cold-shock-enriched cDNAs as probes than when detected using control-enriched cDNAs as probes (data not shown).

\subsection{Northern hybridization analysis}

Northern hybridization was performed using the above five fragments as probes. It appeared that a gene was expressed at low level in naive flies but was clearly upregulated in cold-shocked flies (Fig. 1A). On the other hand, the remaining four genes showed only slight differences between cold-shocked and control flies (data not shown). Using this positive fragment as a probe for Northern hybridization, two bands of approx. 1.2 and $1.0 \mathrm{~kb}$ in length were observed (Fig. 1B). In addition, the signals were considerably stronger in flies given a 2-h cold shock than in the controls, and the signals were stronger in flies cold shocked for $8 \mathrm{~h}$ than in those cold shocked for $2 \mathrm{~h}$ (Fig. 1A).

In insects, HSP70 has been extensively studied in relation to cold shock, but it was induced by heat shock as well as cold shock (reviewed by Denlinger et al., 1991). In yeast, TIP1 gene has been investigated in the relation to cold shock, but the gene was also induced not only by cold but also by heat (reviewed by Thieringer et al., 1998). Therefore, I investigated whether this positive gene could be induced by heat. Northern hybridization revealed that this gene did not respond to heat shock (Fig. 1C).

Henceforth, this positive gene is referred to as Frost, abbreviated as Fst. 


\subsection{RACE}

After sequencing of the Fst fragment, Sub2-R3 and Sub2-F6 primers (Table 1) were designed and used for 5'- and 3'RACE reactions, respectively. Single and double band(s) was(were) amplified in 5'- and 3'-RACE reactions, respectively. These products were subcloned and sequenced using primers listed in Table 1. For 5'-RACE products, ten independent clones were sequenced to obtain the full sequence at the $5^{\prime}$ end of the mRNA. Both long and short $3^{\prime}$-RACE products had $\operatorname{poly}(A)$ tails at the $3^{\prime}$ ends. In addition, they had identical sequences except that the long product had a long $3^{\prime}$ UTR.

Fig. 2 shows full sequence of the long FST cDNA (the combination of 5'-RACE and long 3'-RACE products) with a length of $1,167 \mathrm{bp}$ and an ORF of $834 \mathrm{bp}$ that encodes 278 amino acids (the nucleotide sequence is available from DDBJ/GenBank/EMBL under accession number AB043874). The short CDNA (the combination of 5'-RACE and short 3'-RACE products; 981 bp) had a poly(A) tail from position 959 in the long cDNA (DDBJ/ GenBank/EMBL accession number is AB059240). The lengths of the long and short cDNAs correspond to the bands observed in Northern hybridization. Because the annealing site of Sub2-R3 primer was not in the short cDNA, 5'-RACE reaction using this primer could not amplify the short mRNA (see Fig. 2 and Table 1). The sequence, GTCTAGG, around the terminator codon agrees with the consensus sequence (Kozak, 1986). In addition, this gene had a rapid RNA degradation signal at the 3' end (Fig. 2; Sakai et al., 1989; Yost et al., 1990; Gillis and Malter, 1991). Moreover, it is characteristic that this gene had high internal repeats, especially at the $3^{\prime}$ half of the ORF (analyzed data not shown).

The molecular weight of the deduced polypeptide was $29.3 \mathrm{kDa}$ and the estimated pl was 3.73 . This amino acid sequence was rich in E (glutaminic acid; 16.5\%), T (threonine; $12.5 \%), \mathrm{G}$ (glycine; $11.5 \%$ ) and S (serine; 10.8\%), especially in E (28.3\%), $\mathrm{T}(20.7 \%)$ and $\mathrm{S}(16.7 \%)$ in the C-terminal half of the protein (residues from 134 to 278; Fig.2).

\subsection{Homology analyses}

The homology analyses revealed that the FST cDNA shares little identity to known sequences except to the D. melanogaster unidentified gene, CG9434 (DDBJ/GenBank/ EMBL accession number is AC020051; DAD accession number is AE003683) (Adams et al., 2000), located at position $85 E 2$ on chromosome 3R. The identities are 98.9\% for the nucleotides, and 98.6\% similarity and $99.3 \%$ positive for the protein. Therefore, Fst is apparently the same as the CG9434 gene. However, there is a gap in the alignment analysis between the FST cDNA and genomic sequence of the CG9434 gene; i.e., a gap of 24 nucleotides between position 828 and 829 in the FST cDNA, suggesting that the genome DNA copy contains a 24 nt intron (Fig. 2). In addition to the reports from the Drosophila EST project that this gene was expressed at embryonic and larval-early pupal stages (Berkeley Drosophila Genome Project, personal communication), the present study revealed that this gene also was expressed at a low level in adult flies. There are no reports on the mutant alleles of this gene.

\subsection{Deduced FST protein}

The amino acid sequence also has high internal repeats at the C-terminal half (analyzed data not shown). In fact, FST protein contains nine PEEST (Pro-Glu-Glu-Ser-Thr) sequences (Fig. 2). In addition, this protein has some PEST regions that are thought to mediate rapid degradation of proteins (Rogers et al., 1986).

There is a proline-rich region at the middle of the FST protein. Although this motif is found in small proline-rich proteins (SPRs) cloned from mammals (Kartasova and van de Putte, 1988), its function is still unknown. SPR proteins are components of the cornified cell envelope (CE) of stratified squamous epithelia. In addition, spr genes are expressed in response to UV damage, chemical treatment, and in hyperproliferative or malignant disease (reviewed by Tesfaigzi and Calson, 1999). However, FST protein showed little similarity to SPRs (data not shown).

The hydropathy profile (Kyte and Doolittle, 1982) suggests that this protein has a modular structure; i.e., a short hydrophobic region in the $\mathrm{N}$-terminus and the following hydrophilic region (Fig. 3). The 18 amino acids at the $\mathrm{N}$-terminus have the characteristic features of a signal peptide in both length and amino acid composition (Nielsen et al., 1997). Signal peptides direct proteins into the ER and the protein is thus likely to enter the secretory pathway. On the other hand, particular amino acid sequences at the C-terminus cause proteins to be retained in the ER (Horton and Nakai, 1997), but such sequences are absent in FST. In addition, PSORTII (Horton and Nakai, 1997) also predicts that the protein would be secreted into extracellular space. 


\section{Conclusion}

1. A novel gene (Frost, abbreviated as Fst) was up-regulated during recovery from cold shock in D. melanogaster. A prolongation of cold shock was more effective for induction. In contrast to cold shock, this gene did not respond to heat shock.

2. The complete nucleotide sequence of Fst gene revealed an ORF of $834 \mathrm{bp}$ that encodes 278 amino acids. The putative amino acid sequence is rich in glutaminic acids. In addition, the protein has high internal repeats at the $\mathrm{C}$-terminal half and a prolinerich region at the middle. Moreover, FST protein has a signal peptide at the $\mathrm{N}$-terminal end, suggesting that it would be secreted into extracellular space.

3. Fst gene is apparently the same as the D. melanogaster unidentified gene, CG9434. The gene has at least one intron.

\section{Acknowledgements}

I thank Dr M.T. Kimura from Hokkaido University for his guidance and invaluable advice in this study and Dr D.L. Denlinger from Ohio State University for his critical reading of this manuscript. I also thank to $\mathrm{Dr} \mathrm{H}$. Ito for providing the $r p 49$ probe. The continuous support of members of Ecology and Genetics in the Graduate School of Environmental Earth Science, Hokkaido University is gratefully acknowledged. I especially appreciate the encouragement offered by Dr M.A. Iwasa, Mr H.W. Kitamura and Miss S. Daibo. This study was supported in part by a Research Fellowship from the Japan Society for the Promotion of Science for Young Scientists.

\section{References}

Adams, M.D., et al., 2000. The genome sequence of Drosophila melanogaster. Science 287, 2185.

Denlinger, D.L., Joplin, K.H., Chen, C.-P., Lee, R.E., 1991. Cold shock and heat shock. In: Lee, R.E., Denlinger, D.L. (Eds.), Insects at Low Temperature. Chapman and Hall Press, New York, pp. 131-148.

Denlinger, D.L., Lee, R.E., Yocum, G.D., Kukal, O., 1992. Roles of chilling in the acquisition of cold tolerance and the capacitation to express stress proteins in diapausing pharate larvae of the gypsy moth, Lymantria dispar. Arch. Insect Biochem. Physiol. 21, $271-280$.

Duman, J.G., Xu, L., Neven, L.G., Tursman, D., Wu, D.W., 1991. Hemolymph proteins involved in insect subzero-temperature tolerance: ice nucleator and antifreeze proteins. In: Lee, R.E., Denlinger, D.L. (Eds.). Insects at Low Temperature. Chapman and Hall, New York, pp. $94-127$.

Gillis, P., Malter, J.S., 1991. The adenosine-uridine binding factor recognizes the AU rich elements of cytokine, lymphokine, and oncogene mRNAs. J. Biol. Chem. 266, 3172-3177.

Goodwin, W., Pallas, J.A., Jenkins, G.J., 1996. Transcripts of a gene encoding a putative cell wall-plasma membrane linker protein are specifically cold induced in Brassica napus. Plant Mol. Biol. 31, 771-781.

Goto, S.G., 2000. Expression of Drosophila homologue of senescence marker protein-30 during cold acclimation. J. Insect Physiol. 46, $1111-1120$.

Horton, P., Nakai, K., 1997. Better prediction of protein cellular localization sites with the k nearest neighbors classifier. Intel. Syst. Mol. Biol. 5, $147-152$.

Kartasova, T., van de Putte, P., 1988. Isolation, characterization, and UV-stimulated expression of two families of genes encoding polypeptides of related structure in human epidermal keratinocytes. Mol. Cell. Biol. 8, 2195-2203.

Knight, H., Trewavas, A.J., Knight, M.R., 1996. Cold calcium signaling in Arabidopsis involves two cellular pools and a change in calcium signature after acclimation. Plant Cell 8, 489-503.

Knight, H., Trewavas, A.J., Knight, M.R., 1997. Calcium signalling in Arabidopsis thaliana responding to drought and salinity. Plant J. 12, $1067-1078$.

Kozak, M., 1986. Point mutations define a sequence flanking the initiator codon that modulates translation by eukaryotic ribosomes. Cell 44, $283-292$.

Kyte, J., Doolittle, R.F., 1982. A simple method for displaying the hydropathic character of a protein. J. Mol. Biol. 157, $105-132$.

Monroy, A.F., Sangwan, V., Dhindsa, R.S., 1998. Low temperature signal transduction during cold acclimation: protein phosphatase $2 A$ as an early target for cold-inactivation. Plant J. 13, 653-660.

Nielsen, H., Engelbrecht, J., Brunak, S., von Heijne, G., 1997. Identification of prokaryotic and eukaryotic signal peptides and prediction of their cleavage sites. Protein Eng. 10, 1-6.

Perotti, M., Toddei, F., Mirabelli, F., Vairetti, M., Bellomo, G., McConkey, D.J., Orrenius, S., 1990. Calcium-dependent DNA fragmentation in human synovial cells exposed to cold shock. FEBS Lett. 259, 331- 334.

Rogers, S., Wells, R., Rechsteiner, M., 1986. Amino acid sequences common to rapidly degraded proteins: the PEST hypothesis. Science 234, $364-368$.

Sakai, M., Okuda, A., Hatayama, I., Sato, K., Nishi, S., Muramatsu, M., 1989. Structure and expression of the rat c-jun messenger RNA: tissue distribution and increase during chemical hepatocarcinogenesis. Cancer Res. 49, 5633-5637.

Sambrook, J., Fritsch, E.F., Maniatis, T., 1989. Molecular Cloning: A Laboratory Manual, 2nd Edition. Cold Spring Harbor Laboratory Press, Cold Spring Harbor, New York.

Tesfaigzi, J., Calson, D.M., 1999. Expression, regulation, and function of the SPR family of proteins. Cell Biochem. Biophys. $30,243-265$.

Thieringer, H.A., Jones, P.G., Inouye, M., 1998. Cold shock and adaptation. BioEssays 20, 49-57. 
Thomashow, M.F., 1990. Molecular genetics of cold acclimation in higher plants. In: Scandalios, J.G. (Ed.), Genomic Responses to Environmental Stress, Advances in Genetics, Vol. 28. Academic Press, San Diego, CA, pp. 99-132.

Yost, H.J., Petersen, R.B., Lindquist, S., 1990. RNA metabolism: strategies for regulation in the heat shock response. TIG 6, 223-227. 
Table 1

Nucleotide sequence of primers

\begin{tabular}{llc}
\hline Oligonucleotides & Sequence $\left(5^{\prime}-3^{\prime}\right)$ & $\begin{array}{l}\text { Position of } \\
5^{\prime} \text { base }^{\mathrm{a}}\end{array}$ \\
\hline Sub2-F1 & CCGACTCTGAGGATGATAGCG GTTC & 603 \\
Sub2-F2 & TACCAGTCAGGCACCAGAGGA AATC & 475 \\
Sub2-F5 & GCTCCGGTGACGATGAAA & 129 \\
Sub2-F6 & GTCAGGCACCAGAGGAAATCA CCACCG & 480 \\
Sub2-R1 & ACACGATGTGGGTTCATGAGG CTTC & 1068 \\
Sub2-R3 & TGGGTTCATGAGGCTTCAATC CTAACCC & 1060 \\
Sub2-R4 & AATGGCGAGTGCGTGACATAG TAACACG & 1091 \\
Sub2-R5 & TCCTCAGAACCGCTATCA & 633 \\
Sub2-R6 & TCCGGAGCCTGAGTGGTATCC TCAGAAC & 651 \\
& &
\end{tabular}

a Positions correspond to cDNA in Fig. 2. 


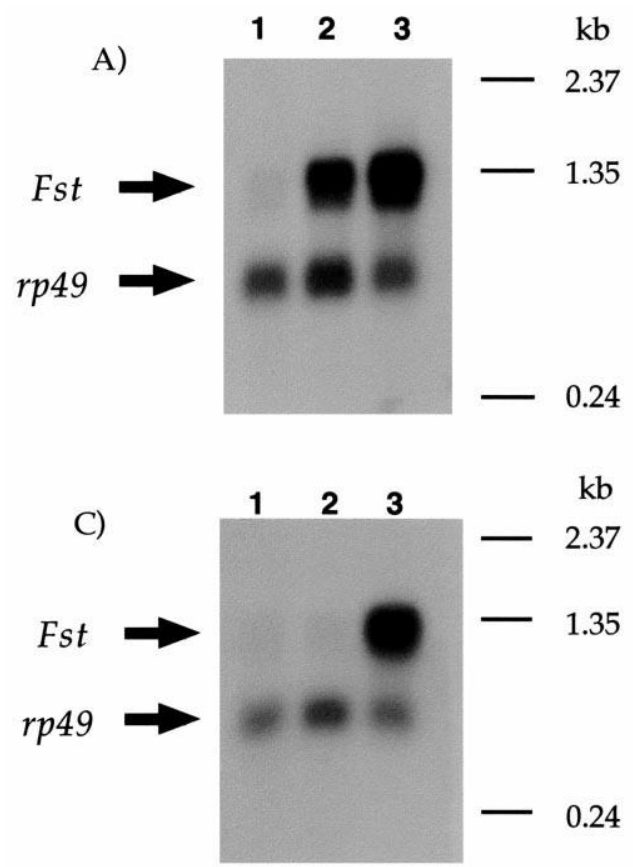

Fig. 1. Northern hybridization analyses using Fst and rp49 probes. (A) Lane 1: control flies (reared at $25^{\circ} \mathrm{C}$ to the 7th day of the adult stage); lane 2: those allowed to recover at $25^{\circ} \mathrm{C}$ for $2 \mathrm{~h}$ after exposure to $0^{\circ} \mathrm{C}$ for $2 \mathrm{~h}$; lane 3: those allowed to recover at $25^{\circ} \mathrm{C}$ for $2 \mathrm{~h}$ after exposure to $0^{\circ} \mathrm{C}$ for $8 \mathrm{~h}$. (B) The details of the signals detected by Fst probe in lane 1 of A (arrow heads indicate bands). (C) Lane 1: control flies (reared at $25^{\circ} \mathrm{C}$ to the 7 th day of the adult stage); lane 2: those exposed to heat at $37^{\circ} \mathrm{C}$ for $30 \mathrm{~min}$; lane 3 : those allowed to recover at $25^{\circ} \mathrm{C}$ for $2 \mathrm{~h}$ after exposure to $0^{\circ} \mathrm{C}$ for $8 \mathrm{~h}$. Positions and sizes of the marker are indicated at the right. Five micrograms of poly $(\mathrm{A})+\mathrm{RNAs}$ were applied to each lane. 
14 ATGAAGGTCCTAACTCTTATCCTCTTCACTGCCTTGGTGGCAGTGGCTTCTGGCCGCCCC 73

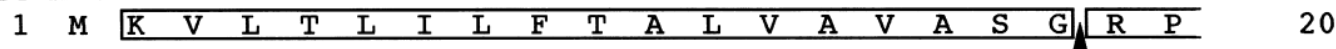

74 AATGGCGGTTGGTTCGGAAATTTTGGCAGCAACTGGGCCAGGAGGTTCGGTTGGGGCTCC 133

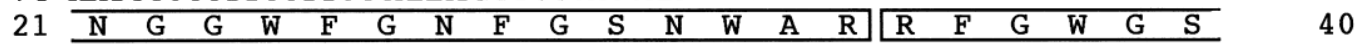

134 GGTGACGATGAAATCGTGCAGGAACAGAGGTGGAATAGCCAAAATCAGTGGAATCCAAAT 193

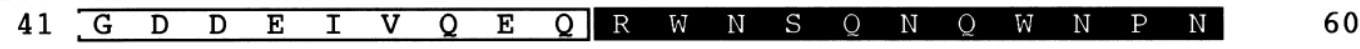

194 GGCAACGGTCAGGGTCAGTGGGATGGCGAAAATGGTCAGGGACAATCTCACGGAAACAAT 253

\begin{tabular}{lllllllllllllllllll|llll}
61 & $G$ & $N$ & $G$ & $Q$ & $G$ & $Q$ & $W$ & $D$ & $G$ & $E$ & $N$ & $G$ & $Q$ & $G$ & $Q$ & S & H & G & N & N & & 80
\end{tabular}

254 CAAGGCCTCGGCCAAGGAAACGGACACGGAAACAACCATCATGGTCATCATGGCAACAAT 313

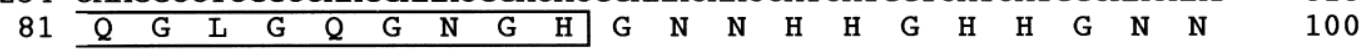

314 CATGGTCATGGTAATGGTCAAGGCCACGGTGGACAGCGCCCTCCTCCACCACCACCAACG 373

$\begin{array}{lllllllllllllllllllllll}101 & \mathrm{H} & \mathrm{G} & \mathrm{H} & \mathrm{G} & \mathrm{N} & \mathrm{G} & \mathrm{Q} & \mathrm{G} & \mathrm{H} & \mathrm{G} & \mathrm{G} & \mathrm{Q} & \mathrm{R} & \mathrm{P} & \mathrm{P} & \mathrm{P} & \mathrm{P} & \mathrm{P} & \mathrm{P} & \mathrm{T} & & 120\end{array}$

374 GATCTGCCTGAGTTGACCACCGAGGATGATGTGGTATCCACCACGGATGTTACCAGTCCC 433

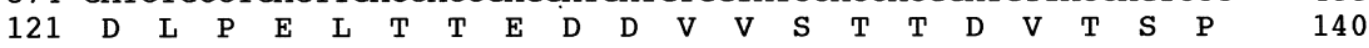

434 GCGGAGGAGACCACTCTGGCACCCGAGgTTCCAGAAGAATCTACCAGTCAGGCACCAGAG 493

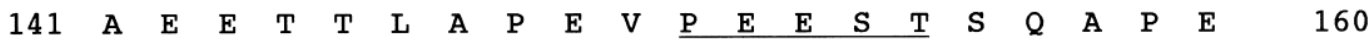

494 GAAATCACCACCGGCTCTGAAGAAGGCAGCGGTTCCTCGGAGGACACCACCACCCTGGCC 553

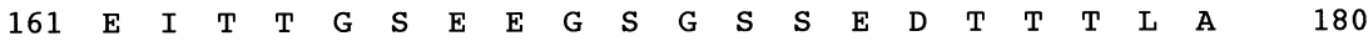

554 CCTGAAGTTCCGGAGGAATCCACCACTCAGGCACCGGAGGAAAGCACCACCGACTCTGAG 613

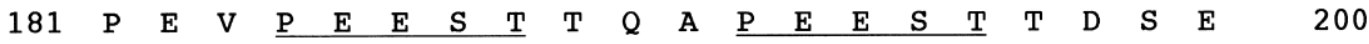

614 GATGATAGCGGTTCTGAGGATACCACTCAGGCTCCGGAAGAAACCACCACCGAGGAGCCT 673

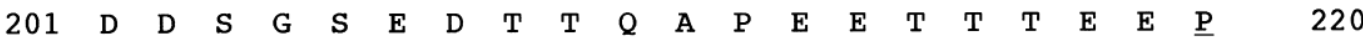

674 GAAGAATCCACCAGCGAGGCTCCCGAAGAATCCACCAGCGAGGCACCCGAAGAATCCACC 733

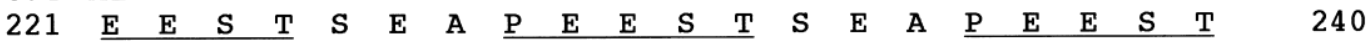

734 ACAGAGGAGCCCGAAGAATCGACAACCGAGGCGCTTGTAGAATCCACAAGTGAGGCACCC 793

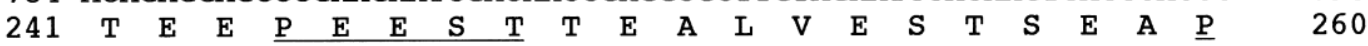

794 GAAGAATCGACGACCGAGGCTCCCGAAGAATCCACTATCGATTCTTCAGCGGTCTAGGAA 853

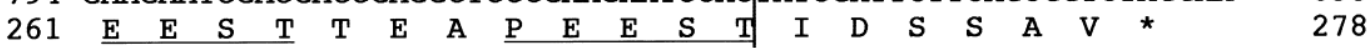

854 GTTAGTTTCATTGTTACCAAGGTTTCTGGTGCATTTTCTCAATAATCGTTTAAAATTTGG 913

914 CGTTTCCGAGTAACAAGGTTATTAAACAAAGCGTTATAAAACGAAATATGGTGCAAATAT 973

974 TAAACTGTTATAGCTAAATTATTAACATGTTCTCCCAGAAGAGCGTAAAACCATTTCTAG 1033

1034 GGTTAGGATTGAAGCCTCATGAACCCACATCGTGTTACTATGTCACGCACTCGCCATTTA 1093

1094 GTTTTATAGCTCCAACAATCTGAACAATTAAAACAACCGAAAAACGAAAAAAAAAAAAAA 1153

1154 AAAAAAAAAAAAA

1167

Fig. 2. Nucleotide (upper row) and deduced amino acid (lower row) sequences of the long cDNA. The termination codon (TAG) is indicated by asterisk. Arrow indicates the putative cleavage site of the signal peptide. The RNA instability signal is shown by double underline. The moderate and weak PEST sequences are indicated by closed and open boxes, respectively. A proline-rich region is indicated by ellipse. Several PEEST sequence repeats are indicated by underlines. Vertical line indicates a putative splicing site. Arrowhead indicates the beginning of poly(A) tail in the short cDNA. The nucleotide sequence is available from DDBJ/GenBank/EMBL under accession number AB043874. 


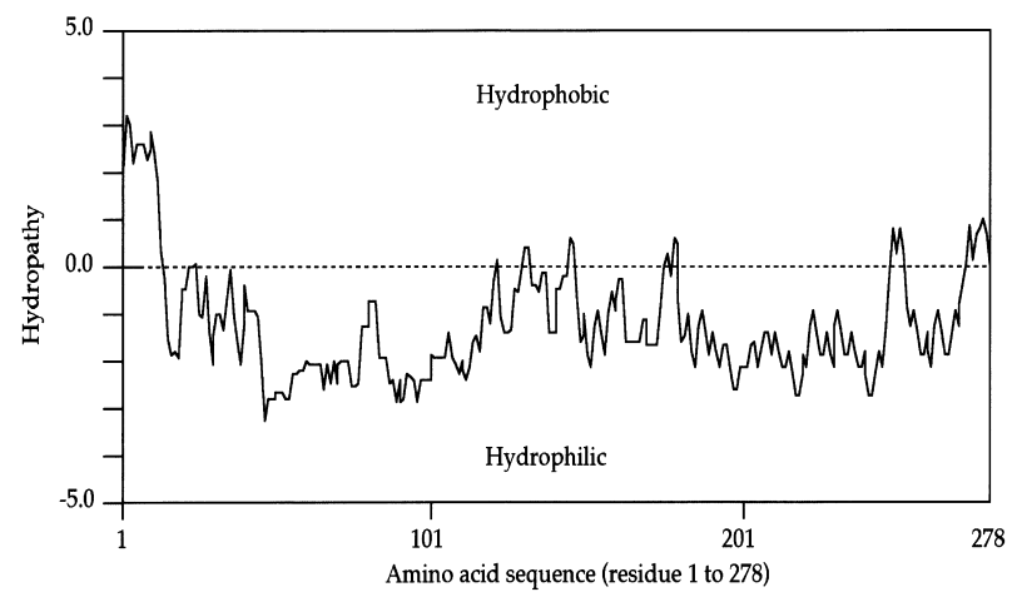

Fig. 3. Hydropathy plot of the predicted FST protein (Kyte and Doolittle, 1982). 